\section{A MATERNITY SERVICE SCHEME*}

\author{
BY
}

\section{DAME LOUISE MCILROY, M.D., F.R.C.P., F.R.C.O.G.}

In opening a discussion on maternity services the startingpoint must be the welfare of the patient and her wishes in the matter. A maternity service scheme must fit in with the general plan of a composite State medical or health service. With the establishment of the Royal College of Obstetricians and Gynaecologists, obstetrics takes its place on an equal footing with medicine and surgery and is not merely a special branch. It has had close collaboration with the public health services. The introduction of antenatal care has given a much wider scope for the practice of preventive medicine, and teaching has expanded beyond the abnormalities of the bony pelvis and the positions of the foetus. The obstetrician now works in collaboration with the orthopaedic surgeon, the paediatrician, the cardiologist, and the tuberculosis specialist. The help of the pathologist and the radiologist is often required for accurate diagnosis, and much more time is now expended upon the clinical examination of the patient than formerly.

Social services also play a large part in the practice of midwifery. Institutional expenditure in other directions could be reduced if we could reduce or eliminate the blindness due to ophthalmia of the newborn. Mental deficiency due to injuries at birth could be lessened to some extent; also tuberculosis, if there were more provision for prolonged residence in sanatoria and facilities for childbirth in these institutions. With more efficient post-natal care the crippling effects of child-bearing upon women would also be lessened. Ante-natal care would lower the neonatal death rate due to prematurity, birth injuries, and malnutrition.

\section{The Economic Aspect}

The economic aspect of maternity practice is of the utmost importance to the State. In my opinion, infant welfare should be under the direction of the paediatricians after the first month of life. Gynaecology cannot be separated from obstetrics, as treatment is required for post-natal complications:

Much of the organization of the maternity services has been haphazard and lacking in co-ordination. This to some extent has been inevitable. New ideas and methods had to be tried out by voluntary organizations and proved of value before public funds could be utilized for anything approaching an experiment. Legislative reforms have brought about great advances in midwifery, such as the various Midwives Acts. Local authorities were given permission to make use of public funds for maternity and child welfare work. It might have been better if in some cases these powers had been made compulsory. The Local Government Act of 1929 made a great advance in the establishment of maternity beds in municipal and county hospitals. The London County Council is an outstanding example of this improvement. It is more satisfactory to have a maternity department in a large general hospital than in isolated units, with the exception of small maternity homes linked up with larger hospitals. In a general hospital auxiliary services are easily obtainable for consultative work, and there is economy of staff and equipment.

\section{Defects in Present Maternity Services}

In building up a scheme it is well to find out what is essential, what is deficient in existing schemes, and what should be avoided. In some areas under a keen medical officer of health the arrangements are excellent and the work with the local practitioners is harmonious. In others the standard of efficiency is low. Neonatal mortality on the whole has been very little reduced during the first twenty-four hours of life. For this the obstetrician must bear the responsibility. The chief defects in our present maternity services are the limited number of beds

* Abstract of opening temarks in a discussion at the Obstetrical Section of the Royal Sc ciety of Medicine, May 15, 1942. in industrial areas. Ante-natal and post-natal beds especially are very inadequate. Emergency cases in rural areas may have to be sent long distances because no beds are available and general hospitals may have little provision for maternity cases.

In the future it is probable that domiciliary midwifery will be still further reduced owing to the difficulties of housing and home service. Flats are unsuitable and are noisy, and women should not have their confinements in slum dwellings.

Rest from household cares and good nursing have a highly beneficial effect upon the nerves of women. These conditions are supplied by hospitals and local maternity homes. Since the war, residents in evacuation areas often are forced to have their confinements in overcrowded homes, as the local maternity homes are booked up for patients coming from cities and towns in more dangerous areas. Convalescent homes are also an important part of a scheme for maternity services, for ante-natal as well as for post-natal cases. Patients are sent out of hospital too soon in some cases owing to pressure upon the beds for childbirth.

Ante-natal clinics in connexion with maternity hospital staffs are satisfactory, as there is continuity of supervision throughout pregnancy and childbirth. In country and municipal ante-natal clinics, however, the assistant medical officer may have had little clinical experience of midwifery, his special qualification being the possession of a diploma in public health. The chances of promotion in such a service, for women especially, are small owing to lack of special training in administrative methods. Local authorities, however, are beginning to recognize this difficulty and to insist upon a diploma in midwifery. If complications arise during pregnancy the patient is sent either to hospital or to a local practitioner who may not be very much interested in her condition as she preferred to attend the clinic at the outset of the pregnancy. In cases where a midwife is in attendance at the confinement a local doctor is called in if any complication arises, and, with no personal knowledge of the patient's previous condition, he may criticize the treatment at the clinic. If the patient is seen later at the post-natal clinic, criticism may be made of the methods employed at childbirth. Midwives who do not work with a recognized team of practitioners serving on a midwifery rota find it not always possible to get help in an emergency, and delay may be serious for the patient concerned.

The fault lies in this practice. of dual responsibility and absence of continuity of supervision. This may be illustrated by the proverb, "Never swap horses while crossing a stream."

In some areas, especially when at a distance from towns, the local practitioners should be chosen as a team because of their competence to practise midwifery, and consultative clinics and services should be available. Facilities for hospital treatment should be readily obtainable. The patient should not be discharged from the supervision of the doctor and midwife until four weeks after the confinement. This would to some extent reduce the difficulties which are met with in breastfeeding.

\section{Voluntary and Municipal Hospitals}

We owe a great debt of gratitude to voluntary organizations and hospitals in midwifery practice. I am glad that $\mathrm{Mr}$. Ernest Brown - the Minister of Health-intends to retain these institutions in a general scheme for medical services. Voluntary contributions will be difficult to obtain after the war, and financial assistance will have to be given by the State if the voluntary hospitals are to retain their individuality. This may mean a loss of administrative control and independence, but the hospitals will gain by being included in the general scheme and given a definite position therein.

This will do away with overlapping and waste of beds in some areas, and will supply accommodation in other areas where hospital resources are inadequate. This would also reduce the long waiting lists for admission and the overcrowded out-patient departments. The voluntary hospitals have done much for teaching by supplying clinical facilities for the medical schools. The healthy spirit of competition does a great deal to make the individual wish to excel. Each special department of the large hospital is sponsored by an honorary head or "chief," who feels himself responsible for its efficiency and, 
by having a say. in the appointment and control of his staff, expects whole-hearted co-operation and loyalty.

Consultants are now paid in hospitals such as those of the London County Council, some being whole-time and others part-time. The question is, Will the future generation of consultants be willing or able to serve as honorary members of the voluntary hospital staff? The answer is not far to seek. The traditions of the voluntary hospitals must not be lost, as they are a bulwark-against a completely socialistic scheme of State service. Co-ordination of the hospitals is being achieved to some extent by the establishment of the Emergency Meoical Service hospitals and by the Nuffield Provincial Hospitals Trust. These are on the lines of central councils and hospitals, with regionalization of areas. The Council of the King Edward's Hospital Fund for London has done much to improve the buildings and equipment of the voluntary hospitals. Would a whole-time State Medical Service give the same incentive to original research as the voluntary system? Would promotion depend upon clinical or administrative ability?

\section{Participation of the G.P.}

In general practice, midwifery has declined to a great extent owing to the efficiency of the midwives services, the establishment of clinics and hospital beds, and also because of the unsuitability of patients' homes. The decline of the birth rate is also a factor.

The national health insurance does not directly include the treatment of midwifery patients, nor does it give special consultant services and hospital accommodation. The panel doctor is too busy to take up midwifery practice with its inadequate remuneration, and he objects to the risk of criticism from local health authorities if cases should go wrong. Cottage hospitals have a limited number of local practitioners in attendance, and others may be excluded from the treatment of their patients when admitted. Small maternity homes should be established where the family doctor can admit and be responsible for the treatment of his own patients. Consultants and auxiliary services should be available from a larger supervising hospital centre.

In rural areas the family doctor would act in a part-time capacity, as he would have to undertake other branches of medical practice. Women prefer local hospitals, where they can be kept in touch with their families and relatives. The family doctor has been the trusted adviser and confidant of his patients as is the priest and lawyer. He is chosen because of the personal element. He knows the home conditions and circumstances as no whole-time practitioner or consultant can know. In official centres case records are open to the inspection of a staff which is under no Hippocratic oath. Consultation clinics do much to relieve the anxieties of the general practitioner, and discussions can take place as to diagnosis and treatment. The family doctor is, moreover, the first line of defence in the case of disease. But the doctor must have adequate training and must keep up to date by regular refresher courses in larger centres.

A team of doctors and midwives working in collaboration with a keen medical officer of health would ensure good results in these areas. Local clinics or centres could be established for interviewing and treating patients, but such centres would have to be instituted by the local health authority, as otherwise there would be difficulties of administration. Payment for work cone would be given by the health authority and collected, when possible, from those patients who could afford to pay or who are specially insured. If any criticism arises it should be considered first by the committee of local practitioners and consultants before being judged by a lay board of management.

In Scotland, domiciliary midwifery is more in the hands of the general practitioners than it is in England and Wales. The midwives work directly under the doctor. The Scottish Board of Health Act, 1937, was a scheme for this co-ordination of practitioners, midwives, and consultants, and it has been established in a large number of areas. Lanarkshire, with its central maternity hospital at Bellshill, is a notable example of its efficiency. The patient has a choice of doctor from the local team of practitioners. The consultants on the staff of Bellshill Hospital must hold the membership or fellowship of the Royal College of Obstetricians and Gynaedit gists.

\section{A Basis for Discussions}

The Russian public health services seem to provide a basis for many discussions on proposals for a State Medical Service in this country. In Russia all mecical education is free and all doctors are whole-time practitioners under the U.S.S.R. The whole aim of the service is the prevention of disease. Every citizen has a right to free medical treatment. Some of the expense is recovered by contributory schemes of health insurance. Women in employment get full pay before and after confinement if off work. The medical practitioners get studyleave and retire on pensions. In the local areas are health centres or polyclinics, and these are linked up with larger centres and hospitals. The teaching schools and fesearch department form the centre of the scheme. Local and central committees or soviets control administration.

A maternity service should give the patient a choice of doctor at the periphery, and consulting and specialist services should work towards the centre. There should be a central advisory committee composed of representatives from the universities, the Royal College of Obstetricians and Gynaecologists, the British Medical Association, Central Midwives Board, College of Midwives, hospitals, and other organizations interested in the practice of midwifery. The administration of such a maternity service should be in the hands of those who have a considerable knowledge of the practical side of obstetrics as well as of public health.

\section{HYPEROSTOSIS FRONIALIS INTERNA*}

BY

\section{T. ANDREWS, M.D., M.R.C.P.}

Physician to the Royal Cornwall Infirmary

Irregular formations of bone on the internal table of the skull have often been observed at post-mortem examinations and among museum specimens, but little notice was taken of the condition until Stewart in this country and Morel in France drew attention to the presence in these cases during life of symptoms suggestive of hypothalamic disturbances.

\section{Cases in the Literature}

Stewart (1927-8) recorded 5 fatal cases personally observed by him and called attention to their association with mental symptoms and obesity; and Morel (1930), describing the first living case, noted the presence of cataleptic seizures, excessive eating and drinking, adiposity, and delusions and hallucinations. There followed various surveys of radiological and museum material with a view to determining the frequency of the syndrome, notably by Sherwood Moore $(1935,1936 \mathrm{a}, 1936 \mathrm{~b})$, who carried out a survey of 6,650 radiographs accumulated over a period of 24 years; by Eldridge and Holm (1940), who described the $x$-ray findings in 200 patients consecutively admitted to a mental hospital ; by Greig (1928), who examined 188 crania in the museum of the Royal College of Surgeons of Edinburgh ; and by Yolton (1927-31), who described 4 specimens. The histories of many of these cases were reviewed, and in the last 12 years numerous additional cases have been published, notably by Van Bogaert (1930), Schiff and Trelles (1932), Eisen (1936), Moniz (1938), Hemphill and Stengel (1940), Gollan (1939), Casati (1936), Fracassi and Marelli (1936), Fattovich (1938), Roger (1938), Perkins and Biglan (1938), James (1936), Lehoczky and Orbán (1938), and Reider (1938-9).

Bartelheimer (1939a, 1939b) specially noted the association with diabetes. The literature on the subject is now fairly extensive, and it is interesting to note in this connexion that only 3 living cases were recorded before 1935-those of Morel (1930), Van Bogaert (1930), and Schiff and Trelles (1932). In view of the large amount of museum material it would seem that many examples of the syndrome were missed prior to that date. This argument, however, is hardly conclusive, for the surveys of radiological and museum material have shown that hyperostoses

* Synonyms : Morgagni's syndrome (Henschen, 1936) ; syndrome of Stewart-Morel (Schiff and Trelles, 1932) metabolic craniopathy (Moore); intracranial osteophytes (Greig, 1' 28). 